
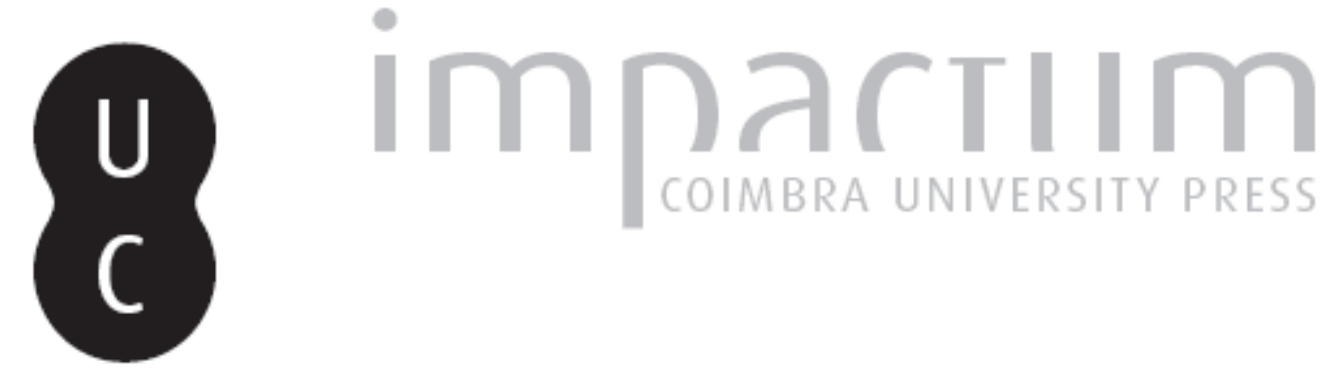

\title{
As diversas faces da venustas, ou intencionalidade estética na arquitectura do Antigo Egipto segundo o Papiro Harris I: o templo egípcio como obra de arte total
}

\author{
Autor(es): $\quad$ Ferreira, J. M. Simões
}

Publicado por: Centro de História da Universidade de Lisboa

URL persistente:

URI:http://hdl.handle.net/10316.2/23721

DOI:

DOI:http://dx.doi.org/10.14195/0871-9527_20_9

Accessed : $\quad$ 26-Apr-2023 15:44:21

A navegação consulta e descarregamento dos títulos inseridos nas Bibliotecas Digitais UC Digitalis, UC Pombalina e UC Impactum, pressupõem a aceitação plena e sem reservas dos Termos e Condições de Uso destas Bibliotecas Digitais, disponíveis em https://digitalis.uc.pt/pt-pt/termos.

Conforme exposto nos referidos Termos e Condições de Uso, o descarregamento de títulos de acesso restrito requer uma licença válida de autorização devendo o utilizador aceder ao(s) documento(s) a partir de um endereço de IP da instituição detentora da supramencionada licença.

Ao utilizador é apenas permitido o descarregamento para uso pessoal, pelo que o emprego do(s) título(s) descarregado(s) para outro fim, designadamente comercial, carece de autorização do respetivo autor ou editor da obra.

Na medida em que todas as obras da UC Digitalis se encontram protegidas pelo Código do Direito de Autor e Direitos Conexos e demais legislação aplicável, toda a cópia, parcial ou total, deste documento, nos casos em que é legalmente admitida, deverá conter ou fazer-se acompanhar por este aviso.

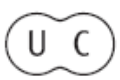




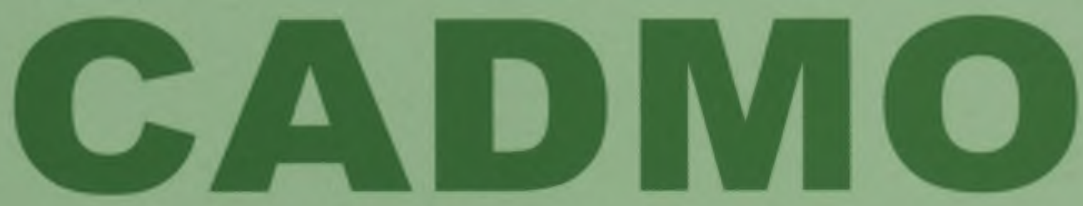

Revista de História Antiga

\author{
Centro de História \\ da Universidade de Lisboa
}

\title{
20
}

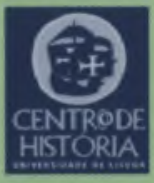

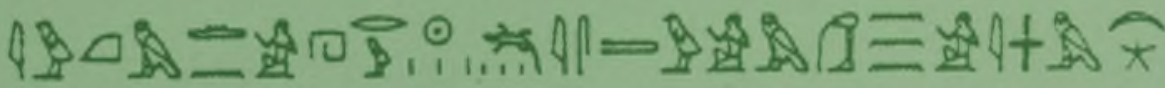

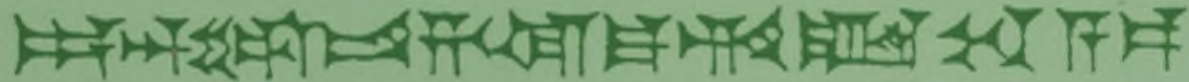

MHNIN AEI $\Delta$ E $\Theta E A ~ \Pi H \Lambda H I A \triangle E \Omega$ 


\title{
AS DIVERSAS FACES DA VENUSTAS, OU INTENCIONALIDADE ESTÉTICA NA ARQUITECTURA DO ANTIGO EGIPTO SEGUNDO O PAPIRO HARRIS I. O TEMPLO EGÍPCIO COMO OBRA DE ARTE TOTAL
}

\author{
J. M. SIMÕES FERREIRA \\ Bolseiro de pós-doutoramento da FCT \\ jm.simoes.ferreira@sapo.pt
}

Se a presença de noções análogas às vitruvianas de firmitas e utilitas $^{(1)}$ na arquitectura do Antigo Egipto, e nos testemunhos literários que a essa arquitectura se referem, ainda que indirectamente, de modo mais implícito do que explícito, não suscita dúvidas ${ }^{(2)}$, o mesmo não acontece com a noção de venustas, ou de algo similar, que se possa considerar que a prefigure. Aí, as dúvidas têm-se feito sentir: com efeito, a arquitectura dos antigos Egípcios, tal como toda a sua arte, tem sido considerada como desprovida de «intencionalidade estética»(3), ou, pelo menos, de consciente intencionalidade estética ${ }^{(4)}$. Obedeceria a imperativos de natureza representacional, mágica e ritualística, conexionados com as suas crenças religiosas, e em que se espelhava a sua cosmogonia e a sua mundividência (Weltanschauung), e não a desejos de expressão ou fruição estética. Visaria objectivos funcionais, não a agradabilidade e o comprazimento dos sentidos, ou a prossecução de uma emoção estética. Em suma, a arquitectura egípcia perseguiria, intencional e conscientemente, a firmeza ou solidez, e a função ou utilidade, mas não o belo (nefer), ou a beleza (neferu), com que não se preocupariam, ou que nunca teriam sido assumidos intencionalmente, de forma auto-consciente, e assim postos 
como finalidades a atingir. - Ora, é isto mesmo o que este artigo se propõe questionar, indagando através de documentos coevos que da arquitectura egípcia, suas características, intenções e finalidades nos dão notícia.

Aquele que é considerado o documento do antigo Egipto mais rico, ou caudaloso, como fonte para a arquitectura, principalmente a arquitectura monumental, e consequentemente para uma hipotética teoria da arquitectura, é o Papiro Harris I (BM 9999) ${ }^{(5)}$, que datará de 1153 a. C., último ano do reinado de Ramsés III, e o primeiro do de seu filho, Ramsés IV ${ }^{(6)}$. Neste documento dá-se notícia de toda uma série de realizações arquitectónicas, feitas ao tempo e sob a égide de Ramsés IV, e no modo como se as refere ou descreve encontram-se expressões indiciadoras das intenções ou finalidades que se perseguiam e que orientavam essas realizações. Entre essas finalidades, parece revelar-se, de um modo nítido, a intencionalidade estética com que eram feitas, que se expressaria de várias maneiras, e cobriria diversos aspectos das mesmas, ou até a sua totalidade. - Veja-se, no intitulado Discurso aos Deuses, Discurso Real, as referências ao templo funerário de Medinet Habu (fig. 1, 2, 3), ao templo de Amon, em Tebas, e a outras obras, em Heliópolis, Mênfis, ou ainda relativas a pequenos templos, noutros locais, disseminados um pouco por todo o país das Duas Terras:

"Fiz para ti um castelo augusto de milhões de anos, instalado sobre a montanha de Nebankh, voltado para ti, construído em pedra de grés, em quartzito e em pedra (de granito) negro, (com) uma porta de electrum e de cobre martelado. Os seus pilones de pedra (talhada) encaravam o céu, (tendo) inscrito, esculpido a cinzel, o grande nome da tua majestade. Construí à volta um recinto de uma feitura perfeita, provido de entradas monumentais (?) (com ?) torres de flanqueamento (?) em pedra de grés. Escavei diante dele um canal cheio de água, plantado de árvores e de plantas como no Baixo Egipto»(7). - Sublinhado nosso.

As expressões que se evidenciaram em itálico, de "castelo augusto", com "feitura perfeita" e "entradas monumentais", parecem ser reveladoras de intencionalidade estética, pois expressa-se nelas todo um sentimento de admiração ${ }^{(8)}$, regozijo e comprazimento perante as características da obra realizada, que se julga revelador de emoção estética. - Mas o texto continua, referindo outras obras de arte, que fariam parte do mesmo monumento funerário: 
«Arrastei estátuas monumentais, grandes como montanhas, em alabastro imaculado (?), esculpidas à imagem da vida, instaladas à direita e à esquerda da (rampa conduzindo ao) seu (= do templo) terraço, e gravadas, para a eternidade, com o grandioso nome da tua majestade. (Arrastei) outras estátuas de granito rosa e de quartzito, e estátuas divinas em granito negro que estão instaladas no interior (= do templo). Dei forma (às estátuas) de Ptah-Sokar, de Nefertum e (dos membros) da Enéade, senhores do céu e da terra, que estão instaladas no seu santuário, cobertas de ouro perfeito, de prata martelada, e incrustadas de pedras preciosas verdadeiras, solidamente cravadas."

«Fiz para ti, no interior (= do templo), um augusto palácio real, semeIhante ao grande castelo de Atum que está no céu, com uma colunata, montantes de porta e batentes de electrum, assim como uma grande janela de aparição de ouro perfeito. ${ }^{(9)}$

A descrição destes trabalhos, em Tebas, de que se salienta a referência a "um augusto palácio real, semelhante ao grande castelo de Atum que está no céu", assinalando a ideia de um "palácio real" na terra, ter como imagem arquetípica, ou seja, como modelo ideal, o palácio ou "grande castelo divino", existente no céu, inclui ainda a referência a "grandes barcas fluviais... carregadas de bens inumeráveis para o seu tesouro augusto "(10), e termina com a evocação dos jardins e pomares que envolveriam o templo. - Veja-se:

«Ele (= o templo) está envolvido por jardins, por pomares, (cujas árvores estão) carregadas de frutos e flores destinadas à tua face. Construí as suas casas de recreio providas de túneis (?), e escavei diante delas (ou deles?) uma bacia ornamentada com lótus.»(11)

Enfim, todos os aspectos de uma obra de arte grandiosa parecem estar contemplados, nesta como que prefiguração de Gesamtkunstwerk, ou "obra de arte total», relativa à arquitectura, artes plásticas, jardinagem, e artes decorativas, cujo intuito seria o de proporcionar um lugar de eleição ao seu futuro habitante, o faraó Ramsés III, que nele iria residir, na sua condição de deus, por "milhões e milhões de anos". O templo tinha por isso de ser não apenas sólido e útil, mas também cómodo e belo. Um lugar singular, impressionante e admirável em todos os aspectos, e no mais amplo sentido. É de reparar na linguagem usada: havia de ser "augusto", de "feitura perfeita", com um aspecto "monumental», recheado de estátuas, "grandes como montanhas, em alabastro imaculado, esculpidas à imagem da vida... cobertas de ouro perfeito, de prata martelada, e incrustadas de pedras preciosas verdadeiras, solidamente cravadas". 
Segue-se depois, a noção do interior do monumento como o lugar mais precioso, onde se instalaria "um augusto palácio real, semeihante ao grande castelo de Atum que está no céu", ressoando nesta expressão toda a mitologia da natureza e origem divina da arquitectura, e das moradas terrenas como cópias ou imitação das celestiais, que seriam o seu arquétipo ${ }^{(12)}$, ou referencial, como modelo ideal.

Por fim, a envolvência por jardins, com "árvores carregadas de frutos, flores... e uma bacia (pequeno lago ou espelho de água) ornamentada com lótus", que contribuiria para simular os ubérrimos Campos de Osíris a que os mortos ilustres teriam acesso, como já antes fora mencionado o canal "cheio de água, plantado de árvores e de plantas como o Baixo Egipto", ou seja, que seria feito à imagem do Baixo Egipto(13), região onde havia mais canais, árvores e plantas.

É de notar que nas referências aos jardins, pomares, bacia e canal, as expressões usadas são: "flores destinadas à tua face... casas de recreio ["maisons de plaisance", no texto em francês] providas de túneis (?)... bacia ornamentada com lótus»; assim, a beleza aqui assinalada visaria já não o belo monumental, admirável e impressionante, essencialmente destinado à contemplação, e ao despoletamento de emoções fortes, mas o da ornamentação decorativa, mais para o agrado e o comprazimento dos sentidos, em termos de vivência quotidiana, além de outros aspectos que parecem ser relativos a usos extraordinários de carácter festivo, como é o caso dos «túneis".

Entre os sentidos distinguir-se-ia o olhar, pois o comprazimento do olhar, ou regozijo contemplativo perante a perfeição e exuberante riqueza das obras, denota-se numa passagem relativa a um templo "em favor dos deuses de Heliópolis". - Veja-se:

«Fiz por ti o meu castelo augusto no interior do teu templo, semelhante ao céu, estabelecido para suportar o disco solar perante ti, provido de fundações em quartzito, revestido (de pedra) d'Ayn ajustada com perícia e assente em teu nome. Aí está o grande horizonte de Horakhti, a grande sede ["siège", que admite a tradução para cadeira ou assento] de ouro, com batentes de porta de ouro fino; a tua mãe aí está instalada [ou sentada] contente e com regozijo de o contemplar. »(14)

A mais tradicional e consensual das definições ocidentais do belo, relativa às artes visuais ou plásticas, logo também abrangendo a arquitectura, como essencialmente consistindo no que agrada ao olhar, encontra-se aqui assinalada, e associada ao registo de emoções (o contentamento, o regozijo) provocadas pela contemplação do 
objecto artístico. Assim, parecendo também aludir a uma atitude distanciada, logo, um sentido da beleza reflexivo, ou seja, já não meramente sensitivo, mas também intelectualizado, como que numa simbiose de intelecto, sensibilidade, e emoção.

No entanto é de notar que não é apenas o aspecto visual, sensitivo ou intelectual, que se apresenta nestes textos, em que chega a ser contemplado o sentido olfactivo, como se explicita na passagem seguinte:

«Plantei e enchi a tua cidade de Tebas, de árvores, de plantas, de rosas e de flores de papiro destinadas às tuas narinas. „(15)

Isto, embora referindo-se à cidade, contribuirá igualmente para entender a importância dada ao envolvimento dos templos funerários com jardins. Havia de atender a todos os possíveis aspectos do prazer, da agradabilidade dos sentidos, da emocionalidade, ou seja, perseguia-se o belo, o agradável, o susceptível de causar prazer, regozijo e admiração de todas as maneiras, havendo ainda de considerar outras, relativas à menção dos utensílios funerários ${ }^{(16)}$, aos livros ${ }^{(17)}$, às barcas processionais e solares ${ }^{(18)}$, aos aspectos festivos dos rituais $e$ do culto(19), etc., sendo que estes últimos não deixariam de incluir a música, o canto, a teatralidade, o movimento compassado, a expressão corporal, a dança...

$E$ é isso que leva a classificar o templo funerário egípcio como uma obra de arte total, seja perseguida mais consciente e intencionalmente, seja-o de um modo inconsciente, produto do «inato sentido da estética» (20) dos artistas ou artesãos egípcios, e dos "directores dos trabalhos do rei»(21), o que, no entanto, a maneira como as diversas componentes dos templos são referidas, no documento interpretado, põe em questão, indiciando-se toda uma atitude de intencional prossecução do admirável, do monumental, do perfeito, do agradável, do susceptível de causar regozijo e comprazimento; enfim, do belo, da beleza, ou da «intencionalidade estética» (a venustas, como Vitrúvio a formularia, e que seria perseguida pelo olhar $\left.{ }^{(22)}\right)$, em todas as suas dimensões de sentido, e de todas as formas em que seria possível exprimi-la: através da arquitectura, da estatuária, da pintura, dos objectos, da escrita, dos jardins, das festas, dos rituais e do culto.

$E$ talvez essa intencionalidade estética, vontade de arte, ou culto da venustas, como a viria a formular Vitrúvio, no sentido de uma intencional (embora talvez não exactamente consciente ou auto-consciente) 
prossecução de tudo aquilo que fosse susceptível de causar admiração, do perfeito, do agradável, do comprazível, em suma, do bom, do bem e do belo (nefer ${ }^{(23)}$ ), nas suas várias facetas e dimensões, assim como da verdade, da ordem cósmica, do direito e da justiça, do equilíbrio e da harmonia, da justa medida e temperança (maet $\left.{ }^{(24)}\right)$, se estenda, como ideal, a todos os domínios da vida, da cultura e da civilização do antigo Egipto, e seja isso, precisamente, que explique o seu tão especial e intrigante carácter; a sua longa duração, que se estendeu por cerca de 3000 anos, dos alvores da civilização até à implantação do cristianismo no Egipto; e o intenso fascínio com que desde muito cedo atraiu e repeliu hebreus, gregos, romanos, e depois o Ocidente. - Mas apresentar uma reflexão sobre tal está fora dos objectivos deste estudo limitado à pesquisa de tópicos que têm a ver com as origens ou prefigurações da teoria da arquitectura.

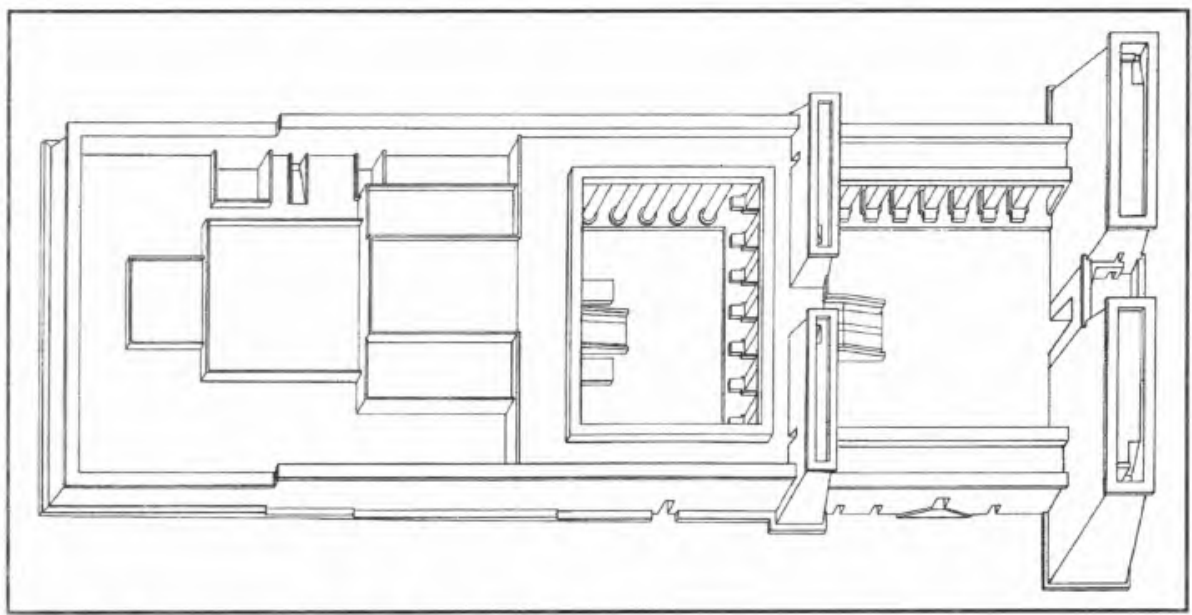

Fig. 1 - Templo funerário de Ramsés III, em Medinet Habu, planta e isometria, in Cenival, J.-L., Égypte. Epoque pharaonique, photos par H. Stierlin, préf. par M. Breuer, Fribourg, 1964, Office du Livre, p. 129. 
Temple de Medinet Habou (suite) 1:1000

Coupe longitudinale, élévation du pylône,

coupe transversale de la cour (côté pylône) coupe transversale de la cour (côté pronaos) coupe transversale de la salle hypostyle
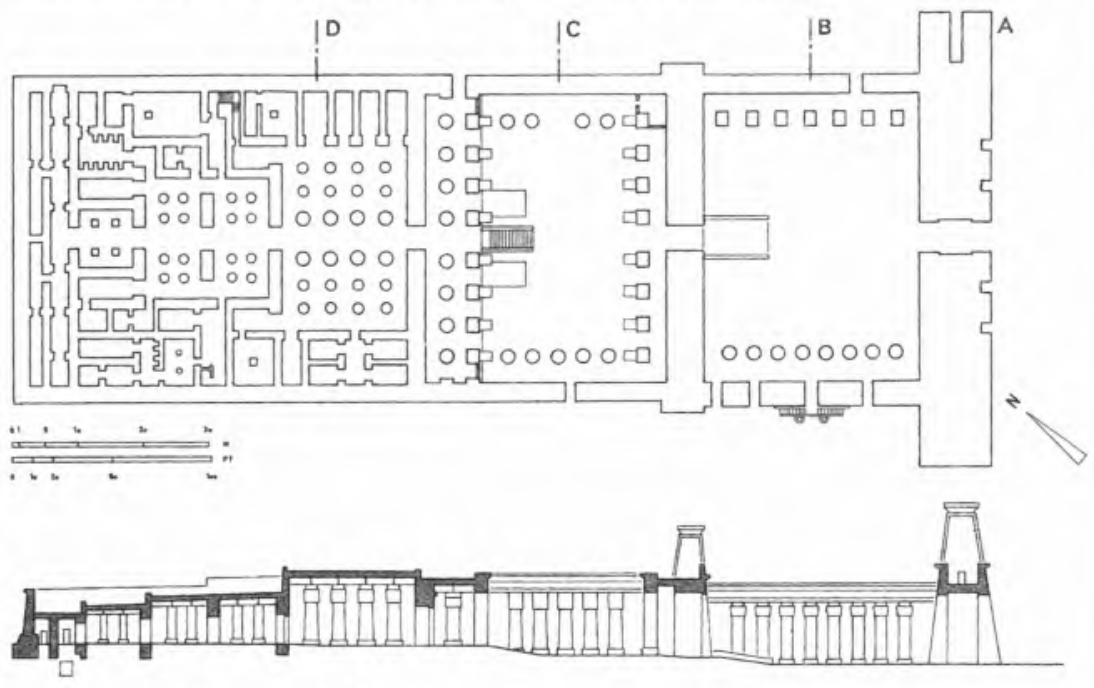
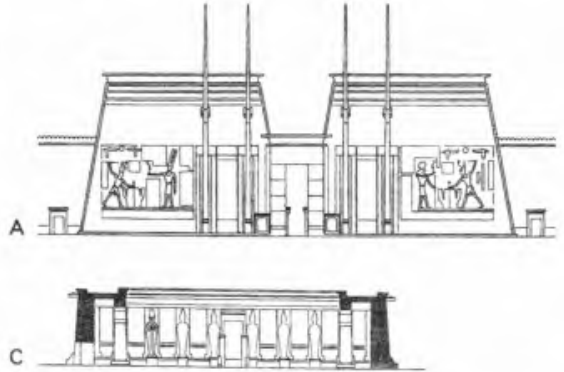

B

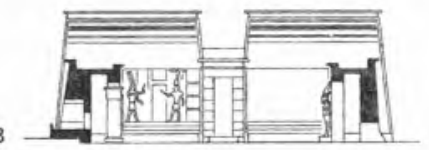

D

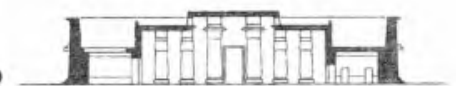

Fig. 2 - Idem, planta, cortes e alçado da fachada principal (entrada), in Cenival, ob. cit. (1964), p. 130. 


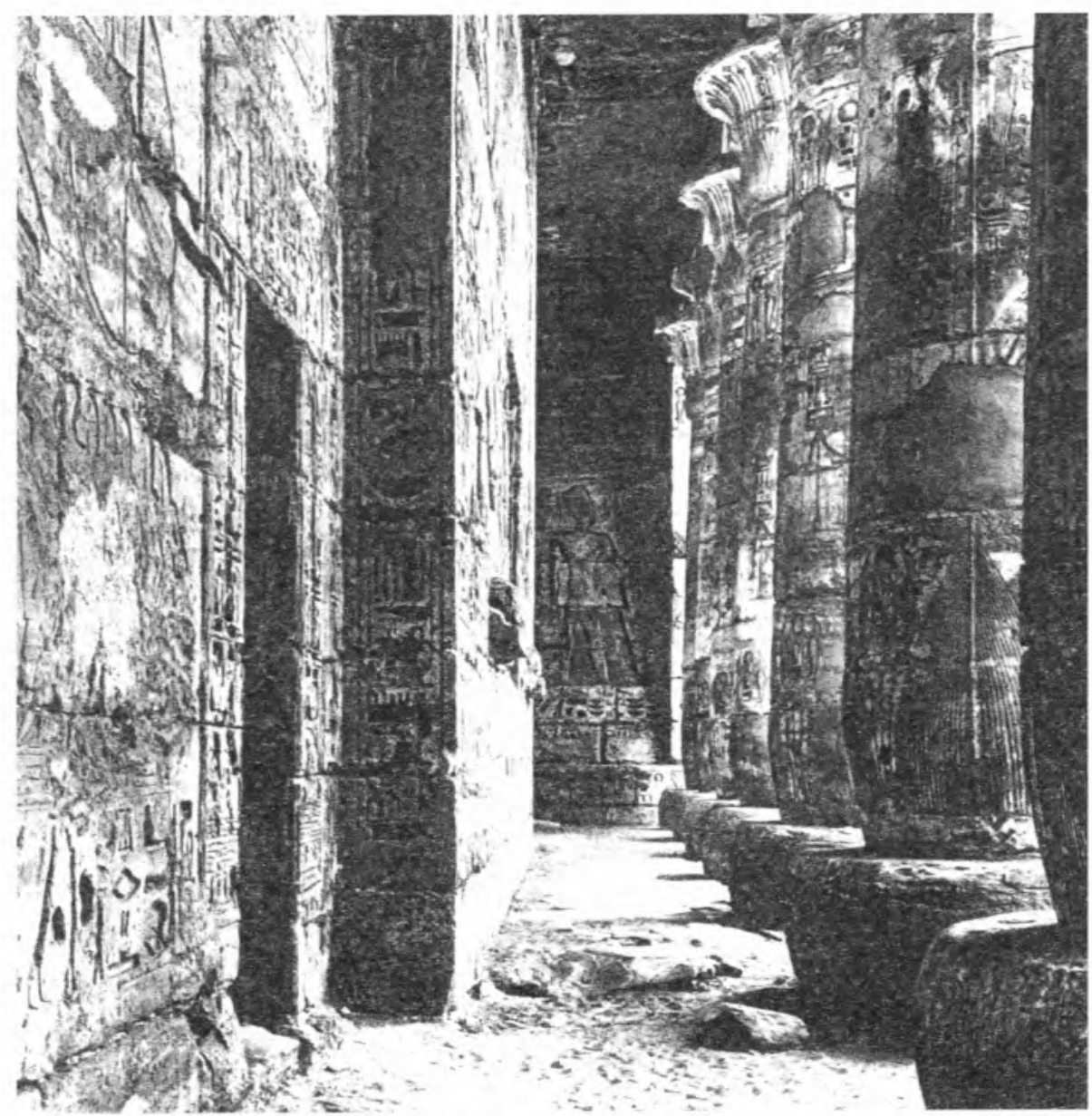

Fig. 3 - Templo funerário de Ramsés III, em Medinet Habu, vista do pórtico sul do primeiro pátio, in Cenival, ob. cit. (1964), p. 124. 


\section{Notas}

(1) VITRUVE, De l'architecture (De architectura), Livre I, C.III, 2, texte établi, traduit et commenté par Ph. Fleury, Paris, 1990, CUF/Les Belles Lettres, p. 20. É no seguimento da menção tipificadora das obras comuns e dos edifícos públicos que a triade vitruviana é explicitada, parecendo referir-se essencialmente a este tipo de edificações. Sobre Vitrúvio, ver: JOLLES, Vitruvius Ästhetik, Friburgo, 1906; SONTHEIMER, Vitruv und seine Zeit, Tubinga, 1908; CHOISY, A., Vitruve, Paris, 1910; BIRNBAUM, A., Vitruvius und die griechische Architektur, Wien, 1914; WISTRAND, E., Vitrustudier, Gotenburg, 1933; PELLATI, F., "Vitruvio nel Medioevo e nel Rinascimento", in Bollettino del Reale Istituto di Archeologia e Storia dell'Arte V, 1933, pp. 111-132; STUERZENACKER, E., Vitruvius über die Baukunst, Essen, 1938; RUFFEL, P. et SOUBIRAN, J., "Recherches sur la tradition manuscrite de Vitruve", in Pallas IX, Fascicule 3 (extrait), Toulouse, 1959; MARTIN, R., "Vitruvius", in Enciclopedia Universal dell'Arte, XIV, 1966, p. 832-837; KNELL, H. e BURKHARDT, H. (eds.), Vitruv-Kolloqium des Deutschen Archäologen-Verbandes, Darmstad, 1984; KNELL, H., Vitruvs Architekturtheorie. Versuch einer Interpretation, Darmstad, 1985; ARNAU Amo, J., La Teoría de la Arquitectura en los Tratados. I: Vitrúvio, Madrid, 1988; CALLEBAT, L., FLEURY, Ph. et altri, Dictionnaire des termes techniques du "De Architectura" de Vitruve, Hildesheim, 1995, Georg Olms Verlag; GROS, P., Vitruve et la tradition des traitès d'architecture: Fabrica e Ratiocinatio. Recueil d'Ėtudes, Rome, 2006.

(2) A firmeza ou solidez, está conexionada com o desejo de perenidade das construções, que deveriam durar "milhões e milhões de anos", e expressa-se em vários tipos de documentos, como os já comentados anteriormente. A utilidade ou o aspecto funcional dos monumentos, tem sido reconhecida consensualmente como o objectivo mais determinante da arquitectura, bem como de toda arte egípcia, que visaria fazer "funcionar" de uma maneira mágica certos aspectos das suas crenças.

(3) Por intencionalidade estética, quer-se referir o conceito basilar de Alois Riegl, de Kunstwollen, tal como é formulado em Stilfragen. Grundlegungen zu einer Geschichte der Ornamentik, Berlin, 1893, e obras posteriores, e tendo em atenção a sua aplicação, por Aldo Rossi, na definição do fenómeno arquitectura: "Creazione di un ambiente più propizio alla vita e intenzionalità estetica sono i caratteri stabili dell'architectura"; ver, L'architettura della Città (1966), Milano, $3 .{ }^{3}$ ed. 1995, p. 9.

(4) É, por exemplo, a tese de Jean Vercoutter: nas obras de arte egípcias não houve a intenção de as fazer "belas" ou "harmoniosas". Ver ARAÚJO, "Arte", Dicionário do Antigo Egipto, pp. 99-110. Note-se que outros autores, como Rainer Stadelmann e Hourig Sourouzian, afirmam ser toda a arte egípcia marcada por um «ideal de beleza". - Ver STADELMANN e SOUROUZIAN, "Schönheitsideal", in Wolfgang Helck e Wolfhart Westendorf (eds.), Lexikon der Ägyptologie, V, cols. 674-676; idem, LEMBKE (ed.), Schönheit im Alten Ägypten. Sehnsucht nach Vollkommenheit (Katalog zur Ausstellung). Hildesheim, 25. Nov. 2006 bis 1. Juli 2007, Karlsruhe, 28 Juli 2007 bis 27. Januar 2008, Hildesheim, 2006.

(5) Ver, GRANDET, Le Papyrus Harris I (BM 9999), ed. crítica, trad., comentários e notas de..., Le Caire, 1994-1999, Institut Français d'Archéologie Orientale, 3 vols. - Foi esta edição que serviu para a interpretação e transcrições, confrontando-a com a de BREASTED, Ancient Records of Egipt, vol. 4, pp. 87-106; e, ainda, tendo em atenção a obra de CHRISTOPHE, Le vocabulaire d'architecture monumentale d'après le Papyrus Harris I, 1961; também PFIRSCH, Les termes d'architecture dans les Textes des Pyramides, 1986.

(6) Embora o Papiro Harris I se apresente com a data do último ano do reinado de Ramsés III, e consista num relato de eventos ocorridos nesse reinado, admite-se "qu'il fut conçu au bénéfice politique de Ramsès IV [seu filho e herdeiro] et que celui-ci, par conséquent - is 
feci cui podest - fut très probablement le maître d'oeuvre de sa réalisation", ver GRANDET, ob. cit. (1994), Commentaire général, § 22 - La fonction du Papyrus Harris, vol. 1, pp. 101-102.

(7) GRANDET, ob. cit. (1994), Trad. du P. Harris I, Discours aux Dieux - Thèbes, Discours Royal $(3,11)-(4,4)$, Vol. 1, p. 227.

(8) Segundo CHRISTOPHE, ob. cit. (1961), p. 18: "La qualité de l'oeuvre architecturale est elle-même notée par une formule stéréotypée: "d'un travail admirable" $(8,8 ; 59,4)$ - aussi pour des statues $(45,8)-$, formule qui a plusiers variantes..."

(9) GRANDET, ob. cit. (1994), id., (4,8)-(4,12), vol. 1, p. 227-28.

(10) GRANDET, ob. cit. (1994), id., (5,1), vol. 1, p. 228.

(11) GRANDET, ob. cit. (1994), id., (5,2)-(5,3), vol. 1, p. 228.

(12) Ver artigo anterior "Sobre a origem divina da arquitectura no Hino ao Templo Eninnu»; idem, AA VV, Dios Arquitecto, Madrid, 1991; SIMÕES FERREIRA, J. M., Visões de Utopia: As Teorias da Arquitectura e as Utopias Políticas nos alvores da Idade Moderna, Lisboa, 2001, FCSH/UNL, 3 vols.

(13) É de lembrar que Tebas, como os gregos Ihe chamaram, se situava no Alto Egipto, parecendo haver nesta caracterização dos jardins um intuito de representação que operaria como que uma transposição mágica do Baixo Egipto para o Alto Egipto. Talvez uma maneira de fomentar a unidade do Duplo País ou País das Duas Terras, como o designavam, reconhecendo as suas diferenças.

(14) GRANDET, ob. cit. (1994), Trad. du P. Harris I, Discours aux Dieux - Héliopolis, Discours Royal $(25,12)-(26,2)$, vol. 1, p. 227.

(15) GRANDET, ob. cit. (1994), trad. du P. Harris I, Discours aux Dieux - Thèbes, Discours Royal $(7,12)$, Vol. 1, p. 259

(16) GRANDET, ob. cit. (1994), id., (4,7), p. 227: "J'ai fait pour elle des récipients de table d'offrande d'or parfait, ainsi que d'autres en argent et cuivre"; ainda referências similares em $(6,3),(6,11)$, etc.

(17) GRANDET, ob. cit. (1994), id., (6,5): «J'ai fait pour toi de grands livres d'or martelé..."; id., $(6,6)$, p. 229: “d'autres livres, en argent martelé»; id., $(6,7)$ : "de grands tablettes, en cuivre martelé".

(18) Estas, "de 130 coudées (de long), au moyen de grands troncs de pin merveilleux des forêts (du Liban), plaqués d'or parfait” (GRANDET, ob. cit. (1994), id., (7,5), p. 230.

(19) GRANDET, ob. cit. (1994), id., (7,4), p. 230: "J'ai institué pour toi des cérémonies d'offrande, comme fêtes du calendrier, à célébrer en face de toi chaque fois que tu apparais, et que sont approvisionnées en pain, bière, bovidés, volatiles, vin, encens et fruits, (en quantité) illimitée"

(20) ARAÚJO, Estudos sobre Erotismo no Antigo Egipto, Lisboa, p. 73.

(21) ROCATTI, La littérature historique sous l'ancien empire égyptien, Paris, 1982, p. 93, nota b.

(22) VITRUVE, De l'architecture (De architectura), Livre III, III, 13, texte établi, trad. et commenté par P. Gros, Paris, 1990, CUF/Les Belles Lettres, p. 21: "Le regard en effet cherche les agréments de la beauté». - No original, em latim: Venustates enim persequitur uisus; na continuação da mesma frase, referindo-se ao jogo das proporçōes, usa a significativa expressão de uoluptati proportione, ou seja, "proporções voluptuosas"... 
(23) Sobre nefer e neferu, ver: STADELMANN e SOUROUZIAN, art. cit., in Helck und Westendorf, ob. cit. (1984), cols. 674-676; idem, ARAÚJO, "Beleza", Dicionário do Antigo Egipto, pp. 146-147; ver ainda LEMBKE (ed.), ob. cit. (2006).

(24) Sobre a maet, ver: ASSMANN, J., Maât, l'Égypte pharaonique et l'idée de justice sociale, Paris, 1989; IDEM, mais desenvolvido, Ma'at. Gerechtigkeit und Unsterblichkeit im Alten Ägypten, München, 1990; ainda em ARAÚJO, "Maet", Dicionário do Antigo Egipto, pp. 524-536 (a dimensão estética da maet é ainda assinalada pelo autor em relação à "harmonia sonora no domínio musical», p. 535). Outros autores, como Erik Hornung e Claire Lalouette, atribuem a maet o significado de "a justa medida das coisas", ou como "designando a ordem, a justa medida, a rectidão, todas as qualidades indispensáveis para a boa marcha do universo"; ver ARAÚJO, artigo e obra acima referidos, p. 526. - Note-se que nestas definições a maet é interpretada como contendo uma dimensão de significado estético, ou ético-estético, se se preferir.

\section{Bibliografia (citada ou referida no texto)}

AA VV, Dios Arquitecto, Madrid: Ediciones Siruela, 1991

ARAÚJO, Luís Manuel de, Estudos sobre Erotismo no Antigo Egipto, Lisboa: Edições Colibri, 1995

ARAÚJO, Luís Manuel de (dir.), Dicionário do Antigo Egipto, Lisboa: Editorial Caminho, 2001,

ARNAU AMO, J., La Teoría de la Arquitectura en los Tratados I: Vitrúvio, Madrid: Tebas Flores, 1988

ASSMANN, Jan, Maât, l'Égypte pharaonique et l'idée de justice sociale, Paris: Éd. Julliard, 1989

Ma'at. Gerechtigkeit und Unsterblichkeit im Alten Ägypten, 2. um ein Nachwort erweiterte Auflage München: C. H. Beck., 2006

AUFRÈRE, S., GOLVIN, J.-Cl., GOYON, J. Cl., L'Égypte restituée. Tome I: Sites et temples de Haute Égypte, $2^{\mathrm{e}}$ éd., Paris: Ed. Errance, 1997

BIRNBAUM, A., Vitruvius und die griechische Architektur, Wien: Hölder, 1914

BREASTED, J. H., Ancient Records of Egipt, Vol. 4, Chicago, 1906, Univ. Chicago Press.

CALlebat, L., FleuRy, Ph. et altri, Dictionnaire des termes techniques du "De Architectura" de Vitruve, Hildesheim, 1995, Georg Olms Verlag.

CENIVAL, J.-L., Egypte. Epoque pharaonique, photos par H. Stierlin, préf. par M. Breuer, Fribourg, 1964, Office du Livre.

CHOISY, A., Vitruve, Paris, 1909, Lahure.

CHRISTOPHE, L.-A., Le vocabulaire d'architecture monumentale d'après le Papyrus Harris I, Le Caire, 1961, Institut Français d'Archeologie Orientale du Caire.

GRANDET, P., Le Papyrus Harris I (BM 9999), ed. crítica, trad., comentários e notas de..., Le Caire: Institut Français d'Archéologie Orientale, 3 vols., 1994-1999

GROS, P., Vitruve et la tradition des traitès d'architecture: Fabrica e Ratiocinatio. Recueil d'Études, Rome: École Française de Rome, 2006 
HÖLSCHER, U., and NELSON, H., Medinet Habu Reports. I: The epigraphic survey 192831. II: The architectural survey 1929-1930, Oriental Institute Communications, 10, Chicago: Univiversity of Chicago Press, 1931

JOLLES, J. A., Vitruvius Ästhetik, Friburgo: C. A. Wagner, 1906

KNELL, H. e BURKHARDT, H. (eds.), Vitruv-Kolloquium des Deutschen ArchäologenVerbades, Darmstad: Technische Hochschule Darmstadt. 1984

KNELL, H., Vitruvs Architekturtheorie. Versuch einer Interpretation, Darmstad, 1985, Wissenschaftliche Buchgesellschaft (reed. 2008).

LEMBKE, K. (Hrsg.), Schönheit im Alten Ägypten. Sehnsucht nach Vollkommenheit (Katalog zur Ausstellung), Hildesheim, 25. Nov. 2006 bis 1. Juli 2007, Karlsruhe, 28 Juli 2007 bis 27. Januar 2008, Hildesheim, 2006, Georg Olms Verlag.

MARTIN, R., "Vitruvius", in Enciclopedia Universal dell'Arte, XIV, 1966, p. 832-837.

PELLATI, F., "Vitruvio nel Medioevo e nel Rinascimento", in Bollettino del Reale Istituto di Archeologia e Storia dell'Arte V, 1933, pp. 111-132

PFIRSCH, L., Les termes d'architecture dans les textes des pyramides, Lille: Univ. Lille 3, 1986

RIEGL, A., Stilfragen. Grundlegungen zu einer Geschichte der Ornamentik, Berlin: Verlag Georg Siemens (reprint, Hildesheim, 1975, Georg Olms Verlag), 1893

ROCCATI, A., La littérature historique sous l'ancien empire égyptien, Paris: CERF, 1982ROSSI, A., L'architettura della Città, 3. ed., Milano: Città Studi Edizioni, 1995RUFFEL, P. e SOUBIRAN, J., "Recherches sur la tradition manuscrite de Vitruve", in Pallas IX, fascicule 3 (extrait), Toulouse, 1959

SIMÕES FERREIRA, J. M., Visões de Utopia: As Teorias da Arquitectura e as Utopias Politicas nos alvores da Idade Moderna, 3 vols., Lisboa, Faculdade de Ciências Sociais e Humanas, Universidade Nova de Lisboa, 2001

SONTHEIMER, L., Vitruv und seine Zeit, Tubinga: J. J. Heckenhauer, 1908

SOUROUZIAN, H., "Schönheitsideal", em Helck, W. e Westendorf, W. (eds.), Lexikon der Ägyptologie, V, Wiesbaden: Otto Harrassowitz, 1984, cols. 674-676

STADELMANN, R., "Medinet Habu", em Helck, W. e Otto, E. (eds.), Lexikon der Ägyptologie, III, Wiesbaden: Otto Harrassowitz, 1979, cols. 1255-1271

STUERZENACKER, E., Vitruvius über die Baukunst, Essen: Bildgut Verlag, 1938

VITRUVE, De l'architecture (De architectura), Livre I, texte établi et trad. par Ph. Fleury, Paris: CUF/Les Belles Lettres, 1990

De l'architecture (De architectura), Livre III, texte établi, trad. et commenté par P. Gros, Paris: CUF/Les Belles Lettres, 1990

WISTRAND, E., Vitrustudier, Gotenburg: Eranos, 1933 